\title{
Econometric model of non-performing loans determinants
}

\author{
Nikola Radivojević ${ }^{\mathrm{a}}$, Drago Cvijanović ${ }^{\mathrm{b}}$, Dejan Sekulic ${ }^{\mathrm{b}}$, Dejana Pavlovic ${ }^{\mathrm{c}}$, \\ Srdjan Jovic ${ }^{\mathrm{d}, *}$, Goran Maksimović ${ }^{\mathrm{i}}$ \\ a Technical College at Applied Studies, Kosovska 8 Street, 34000 Kragujevac, Serbia \\ ${ }^{\mathrm{b}}$ Faculty of Hotel Management and Tourism in Vrnjačka Banja, University of Kragujevac, 5A Street, 36210 Vrnjačka Banja, Serbia \\ ${ }^{\mathrm{c}}$ Institute of Economic Sciences, Zmaj Jovina 12 Street, 11000 Belgrade, Serbia \\ d University of Priština, Faculty of Technical Sciences, 38220 Kosovska Mitrovica, Kneza Milosa 7, Serbia \\ e University of Priština, Faculty of Agriculture, Kopaonička, 38219 Lešak, Serbia
}

\section{H I G H L I G H T S}

- To point out the theoretical advantages of GMM in relation to other (often used) panel data estimators.

- To demonstrate its advantages in the case of the emerging markets in the countries of Latin America.

- To identify a relevant econometric model.

- To demonstrate the impact of crucial macro and microeconomic variables on the NPLs.

\section{A R T I C L E I N F O}

\section{Article history:}

Received 26 September 2018

Received in revised form 19 December 2018

Available online 15 January 2019

\section{JEL classification:}

G24

C22

C52

C53

Keywords:

General moment method

Non-performing loans

Macroeconomic variables

Microeconomics variables

Banking system

Dynamic panel

\begin{abstract}
A B S T R A C T
The paper presents the use of the difference GMM and the system GMM for the purpose of determining the critical determinants of non-performing loans. The aim of the paper is to point out the theoretical advantages of GMM in relation to other (often used) panel data estimators in the study of NPLs, and to demonstrate its advantages in the case of the emerging markets in the countries of Latin America. The paper seeks to identify a relevant econometric model in order to demonstrate the impact of crucial macro and microeconomic variables on the NPLs. No evidence was found in support of the significance of the impact of the inflation rate and the microeconomic variables that were the subject of research in this paper.
\end{abstract}

(c) 2019 Elsevier B.V. All rights reserved.

\section{Introduction}

The general and well-known fact is that the stability of the banking system is one of the major preconditions for economic growth of every society, since the banks play a vital role in allocating capital from capital-sufficient agents to capital-deficient participants in the economic life of the society [1]. However, the structural changes that have taken place in the international financial market during the last years of the twentieth century, accompanied by deregulation and internationalization of

\footnotetext{
* Corresponding author.

E-mail address: srdjanjovic2016@hotmail.com (S. Jovic).
} 
banks' activities, have influenced the increase of competition among the banks. The strengthening competition between banks affected the banks' increased credit risk, i.e. influenced the relaxation of their borrowing criteria and screening procedures, which lead to the erosion of the quality of the banks' lending activity, that is, the increasing rate of nonperforming loans (NPLs) (e.g. [2-4]). The quality of the loan portfolios, before the financial crisis in the previous decade of this century, was relatively stable. Thereafter, the quality of their loan portfolios deteriorated sharply. The deterioration of the quality of banks' loan portfolios caused the growth of the level of NPLs. So today, this problem is almost equally evident in both developed and emerging countries. According to Makri et al. [5], only extreme growth of the NPLs level should be expected in the forthcoming period, which will have a negative effect on the global macroeconomic stability.

The speed of growth of the NPLs rate on the one hand, and its potential consequences on the other, have influenced the NPLs studies of occurrence, movement and determinants to become an inevitable topic in the banking and academic circles, as well as the subject of much research. Unfortunately, numerous studies based on the use of panel data in the study of this phenomenon resulted in contradictory conclusions, first of all in terms of direction, intensity and significance of macro and micro determinants of NPLs. To some extent, the differences in findings can be described by differences in panel data, but some of the disagreements and contradictions in discoveries and findings can be attributed to differences in the methods used for the estimation of the parameters of the panel data models.

The differences in the findings are evident, not only in terms of the intensity and significance of individual factors in the occurrence and movement of NPLs, but also in terms of sign. So, for example, many authors like [5-10] point out that ROA and ROE are the most important indicators of efficiency, profitability, i.e. the quality of bank management, but they found different impact these factors to NPLs. Godlewski [6],Radivojevic and Jovovic [10] found that there is a negative and significant correlation between these factors and NPLs, while Garsiya and Fernandez [7] and Boudriga et al. [8] identified positive relationship between these factors and NPLs. It is similar with other macro and micro factors of NPLs (such as unemployment rate, interest rate, exchange rate, house price index, market capitalization, the bank's capital to assets ratio, size banks, ER, loan loss provision and etc.). Salas and Saurina [11] found that the net interest margin ratio (NIMR) does not affect NPLs. On the other hand, Espinoza and Prasad [12] showed that there is a significant relationship between this factor and NPLs. Babouček and Jančar [13], Rinaldi and Sanchis-Arellano [14], Nkusu [15], Mileris [16], Figlewski et al. [17] and Radivojevic and Jovovic [10] studied the influence of macroeconomics factors on NPLs and found that INF affects NPLs positively. Controversial findings were reported by Jovovic [18] and Shu [19], while the results of the study conducted by Skarica [20] show that this factor does not have an impact on NPLs. Similar examples can be found in the study of other variables. Skarica [20] reported that the share price index (SPI) does no affect NPLs, while Beck et al. [21] showed that there is a negative and significant relationship between the SPI and the NPLs rate. Also, Skarica [20] reported statistically insignificant dependency between NPL ratio and interest rate (IR). On the other hand, Rajan and Dahl [22], Hoggarth et al. [23], Saurina and Jiménez [24] and Saba [25] point out there is a strong correlation between the IR and the NPLs. The findings obtained by De Bock and Demyanets [26] imply that exchange rate (ER) is one of the main determinant of NPLs, as opposed to Klein's discovery (2013) that the ER has no significant impact on the NPLs. It is interesting to note that all researchers agree on the impact of GDP on NPL. All reported a statistically significant and negative impact of this macro factor on the occurrence and movement of NPLs. Also, it is interesting to note that the authors themselves presented different findings when used by different estimators. An interesting example is Pouvelle [27], who used a three-stage least square estimator with fixed effects in his study. As a robustness check, he used different estimators, and his results were unchanged, only in regards the signs of the main variables' coefficients.

However, for the estimation of parameters, the authors used various estimators, starting with simple techniques, such as pooled Ordinary Least Square (OLS) or two-stage Least Square (2SLS), via Dynamic Fixed Effect (DFE) and Random Effect (RE), up to the one or the two-steps (difference or system) GMM estimator. For example, Stakic [28] used only pooled OLS in his research. The use of this estimator is highly questionable. Namely, in the sixties of the previous century, Mandelbrot [29] and Fama [30] demonstrated that the data series from financial markets were not identically and independently distributed, but that they are distinguished by the presence of autocorrelation and heteroscedasticity. In these circumstances, pooled OLS generates a biased and inconsistent estimates. The widely used estimator is DFE. This is understandable when considering that there is a realistic expectation that each entity has its individual specificities that may or may not affect the predictor or behavior of dependent variable or bias, and therefore it is recommended to use FE estimator. In other words, it allows to capture the time-constant unobserved heterogeneity between entities (countries). According to Wooldridge [31], it allows to remove the effects of those time-invariant characteristics, in such a way that it allows the predictor's net effect to be assessed only. However, it suffers from the "dynamic panel bias" problem, which results from the possible endogeneity of the lagged variable and the fixed effects in the error term [32]. The problem of the possible endogeneity of one or more explanatory variables can be solved using 2SLS estimator, but under the assumption that instrumental variables are not weak. Otherwise, biased estimates are obtained. In addition, one should bear in mind the claim of Pesaran et al. [33]. They state that, in the case where the $T$ dimension is larger than the $N$ dimension, "Traditional procedures for the estimation of pooled models produce inconsistent, and potentially very misleading estimates of the average values of parameters in dynamic panel data models". The common characteristic of all these estimators is that they can produce unbiased and consistent estimates of parameters only if the assumptions on which they are based are met. Unlike other estimators, the main advantage of GMM is that it can be used even when the assumptions of other estimators are not satisfied. Generally speaking, GMM can be viewed as a generalization of many other methods (see [34]). Therefore, the main purpose of the paper is to point out the theoretical advantages of GMM in relation to other (often used) panel data estimators in the study of NPLs, and to demonstrate its 
advantages in the case of the emerging markets in the countries of Latin America. The aim of the paper is to identify a relevant econometric model in order to demonstrate the impact of crucial macro and microeconomic variables on the NPLs.

The paper is organized as follows: Section 1 contains the introduction, in which the motive, purpose and aim of the paper are outlined. Section 2 presents a theoretical background of the GMM. Section 3 gives a brief outline of the advantages of using GMM in relation to other estimators, in the context of examining key determinants of occurrence and movement of NPLs. Section 4 provides description of the analyzed data, the descriptive statistics of selected emerging markets. In this part of the paper, the results are presented, analyzed and discussed. The final section summarizes the conclusions.

\section{Theoretical basis of the GMM}

The GMM is a very powerful and general estimation method [35], whose power is reflected in the fact that its usage is effective even when the assumptions of other estimators are not met. In other words, it generates correct standard errors and p-values, provided that the specified moment conditions are valid. It is based on a simple idea that the estimations of parameters are done by solving a set of moment conditions.

The GMM is simple to understand and easy to implement. Its implementation is done in a few steps. Under assumption that DGP satisfies (m) distinct moment conditions:

$$
E\left[g_{i}\left(\theta_{0}\right)\right]=0
$$

for the observations $i=1, \ldots, n$, where the $\left(g_{i}\right)$ are known functions $g_{i}: R_{p} \rightarrow R_{m}$ that depend on the observed data, the first step in the implementation of the GMM involves identifying the $(p)$ unknown parameters of the parameter vector of interest $(\theta)$ and specifying the $(m)$ moment restrictions.

The second step in implementation of the GMM involves estimating the parameter $(\theta)$ by solving the system of the $(m)$ equations obtained by replacing the population mean $(E)$ in $(2.1)$ by the sample mean $\frac{1}{n} \sum$ that is:

$$
\frac{1}{n} \sum_{i=1}^{n} g_{i}(\theta)=0
$$

This is true if and only if the number of equations $(m)$ is equal to $(p)$ (so-called the exactly identified case). In situation when the number of equations $(m)$ is more than the number of unknown parameters $(p)$ (the over-identified case) there is no exact solution of the system of equations. In this case, the estimate of the parameter $(\theta)$ is done by minimizing a weighted sum of squares:

$$
\frac{1}{n} G_{n}^{\prime} \mathrm{WG}_{n}
$$

where $G_{n}(\theta)=\sum_{i=1}^{n} g_{i}(\theta)$ and $(W)$ is an $(m) \mathrm{x}(m)$ symmetric and positive definite matrix, known as the weights matrix. In this case the choice of $W$ is crucial, because of the possible differences in sampling variation of the individual moment conditions. There are at least two different choices of $W$. The weighting matrix $W$ can be chosen iteratively, starting with $W=I$ and (if $\hat{\theta}_{h}$ is the estimate obtained in th $h$ th iteration) choosing in the $(h+1)$ st iteration $W=J_{h}^{-1}$, where $J_{h}=\frac{1}{n} \sum g_{i}\left(\hat{\theta}_{h}\right) g_{i}^{\prime}\left(\hat{\theta}_{h}\right)$ (Heij, et al., p. 259). Choosing $W=J_{h}^{-1}$ to be the inverse of a consistent estimator $\hat{J}$ of $J$ will minimize the asymptotic variance of the GMM estimator. This leads to a two-step GMM estimator. The two-step GMM is usually used, since it has a better efficiency than the one-step GMM, and its application improves the power of the associated tests. The two-step GMM and the associated tests have the same asymptotic properties as the corresponding ones when the optimal weighting matrix is known. However, given that the optimal weighting matrix is estimated nonparametric in the time series setting, there is a large estimation uncertainty [36, p. 2]. For this reason, they recommend using the two-step GMM only when the benefit of using the optimal weighting matrix outweighs the cost of estimating it.

The next step involves calculating standard errors. They are, in fact, the square roots of the diagonal elements of the estimated covariance matrix of $\hat{\theta}$, which can be mathematically expressed in the following way:

$$
\hat{\operatorname{Var}}(\hat{\theta})=\left(H_{n}^{\prime} J_{n}^{-1} H_{n}\right)^{-1}
$$

where

$$
J_{n}=\sum_{i=1}^{n} g_{i}(\hat{\theta}) g_{i}^{\prime}(\hat{\theta}), \quad H_{n}=\sum_{i=1}^{n} \frac{\partial g_{i}(\hat{\theta})}{\partial \theta^{\prime}}
$$

The final step in implementation of the GMM is to test the validity of the moment conditions using the Sargan or the Hanse-n - J test (in over-identified models):

$$
G_{n}^{\prime} J_{n}^{-1} G_{n} \approx \chi^{2}(m-p)
$$

In the exactly identified case, the moment conditions cannot be tested, as $G_{n}(\hat{\theta})$ will be identically zero irrespective of the question whether the imposed moment conditions are correct or not [37]. 
Based on the above, it can be concluded that the GMM's efficiency depends on the defined moment conditions. The set of moment conditions for which $H_{0}$ is large and $J_{0}$ is small (all in the sense of positive definite matrices) are the best. $H_{o}=\frac{\partial G}{\partial \theta^{\prime}}$ is large when the violation of the moment conditions (1) is relatively strong for $\theta \neq(\hat{\theta})$, while $J_{0}$ is small when the random variation of the moments $g_{i}\left(\hat{\theta}_{0}\right)$ in $(1)$ is small.

Since GMM depends only on moment conditions, it is a reliable estimation procedure for many models in economics and finance [34]), especially for models which suffer from endogeneity problems, because it provides the efficient estimations of instrumental variables, under "orthogonality condition", instrumental variables and error term being orthogonal in the expectation sense. Unfortunately, the GMM is not unbiased in general, because in finite samples the instruments are generally not perfectly uncorrelated with the endogenous components of the instrumented repressors' [38]. Numerous papers have dealt with this problem and its effects in the finite samples (Carrasco [39]).

\section{Reasons for using GMM in examining the NPL issue}

As mentioned in the introductory part, in the study of the NPL issue, it is common to the use a dynamic panel data model, in the following fashion:

$$
\mathrm{NPL}_{i, t}=\beta_{0} \mathrm{NPL}_{i, t-1}+\beta_{i} X_{i, t}+\varepsilon_{i, t}
$$

$$
\text { with } \varepsilon_{i, t}=\eta_{i}+v_{i, t}
$$

where the subscripts $i$ and $t$ denote the cross sectional and time dimension of the panel sample respectively, $N P L_{i, t}$ is nonperforming loans, $N P L_{i, t-1}$ is its lagged value, $\beta_{i}$ is $1 \mathrm{xk}$ vector of parameters, $X_{\mathrm{i}, \mathrm{t}}$ is the $1 \mathrm{xk}$ vector of explanatory variables, $\varepsilon_{i, t}$ is the error term, which has two orthogonal components: $\eta_{i}$ are the unobserved individual effects and $v_{i, t}$ are the observed specific errors.

The basic purpose of using a panel data analysis in this kind of investigations is to discover whether there is any pattern in the data collected in different countries over time (cross-sectional between different countries). In other words, it is useful for capturing country-specific effects and the unobservable differences between countries, which allows control over the biases generated by potential heterogeneity and omitted variable problems. The use of dynamic analysis allows to perceive the time persistence in the NPLs structure, including the lagged dependent variable the in right-side of Eq. (3.7). However, for estimation equation (3.7), authors use different estimators. Some are more and the other less suitable for estimating Eq. (3.7) given the following potential problems that may arise from estimate of Eq. (3.7).

First, in Eq. (3.7) lagged dependent variable is possible correlated with the fixed effects in the error term, which leads to "dynamic panel bias". In these circumstances, applying OLS and FE methods will result in biased and ineffective estimates. As pointed out in the introduction, one of the solutions is to apply 2SLS, but provided the instruments are not weak [40]. Otherwise, the results will be the same as in the previous case. A valid solution is the application of the difference GMM introduced by [41]. It is based on a first-order difference transformation (transformation data by first-order difference), which allows to eliminate the fixed effect, as well as the used lagged levels of the right hand-side variables as instruments. Although the fixed effect is eliminated by using difference, the lagged dependent variable is still correlated with observed specific errors, causing bias in estimation of parameters. Since it is realistic to expect that $N P L_{i, t-2}$ is highly correlated with differenced $N P L_{i, t-1}$ but not with error term, it is $N P L_{i, t-2}$ valid instrument, as long as the $v_{i, t}$ is not serially correlated.

Second problem in Eq. (3.7) is the bias due to the possible endogenous of the explanatory variables with the error term. Instead of using only exogenous variables, endogenous variables are predetermined in the different GMM. It makes that they uncorrelated with the error term in Eq. (3.7). Strictly exogenous regress, as well as any other instruments, can enter the instrument matrix in the conventional instrumental variables fashion: in first differences, with one column per instrument. For a set of weakly exogenous or predetermined explanatory variables, only current and lagged values of are valid instruments (Louzis, et al. p.19). A problem is that lagged levels are often poor instruments for first differences, especially for variables that are close to a random walk. Furthermore, with the absence of some original data, in the panel data, the difference GMM magnifies gaps, because in this case, two transformed data are missing. This leads to the situation that it is possible to build a set of data that completely disappears in the first differences. According to Roodman [38] this leads to the situation that it is possible to build a set of data that completely disappear in first differences. Blundell and Bond [42] and Klein [32] reported that in samples with small time dimension and high persistence, the estimation has low precision. The reason is that the growth of persistency of the series causes the lagged levels to become less correlated with subsequent changes so they turn out to be weak instruments Blundell and Bond [see42]. This may be a motive for the use of another kind of transformation, "forward orthogonal deviations" proposed by Arellano and Bover [43], which has additional assumption about the non-correlation between the fixed effect and the first differences of instrumenting variables. This allows the introduction of additional instruments and leads to an increase in the effectiveness of the estimation, but also to an increase in bias. A good feature of this trans-fraction is that if the variables are independently distributed before trans-fraction, they remain after it. 
Table 1

Summary descriptive statistics of data set.

Source: Author's calculations.

\begin{tabular}{llllll}
\hline Variables & Missing Obs. & Mean & Std. Dev. & Minimum & Maximum \\
\hline NPL & 4 & 4,79 & 4,96 & 0,51 & 33,90 \\
GDP & 0 & 3,86 & 4,02 & $-10,90$ & 18,29 \\
UNR & 0 & 7,38 & 3,38 & 2,50 & 18,30 \\
INF & 0 & 8,85 & 13,25 & $-1,07$ & 121,74 \\
HFC & 0 & 3,90 & 4,73 & $-16,87$ & 16,89 \\
CAR & 1 & 8,71 & 3,59 & 8,00 & 15,90 \\
LIR & 0,00 & 21,68 & 18,50 & 3,42 & 118,38 \\
\hline
\end{tabular}

The third problem with Eq. (3.7) is that the presence of $N P L_{i, t-1}$ lagged dependent variable leads to auto relation. However, by applying differentiation, it is instrumented with its past levels. Finally, it should be pointed out that in Eq. (3.7), it is possible that the $T$ dimension be small. In the situation when $T$ is large, the impact of the fixed effects decreases with the time, and correlation between $N P L_{i, t-1}$ and error term will be insignificant (see [38]). In this situation, the use of both the difference and system GMM, which were designed for small $T$ and large $N$ dimension, is not necessary. Also, you should not lose sight of the Pesaran et al. [33] statement about the inefficiency of traditional pooled estimators.

\section{Empirical analysis}

The growth of the rate of NP is a global phenomenon, which has gained importance since the appearance of the world of economic crisis. Although the deterioration in the quality of the loan varies considerably from country to country, the slowdown in the economy, and the deterioration of the financial strength of the borrower, due to high inflation and devaluation and depreciation of national currencies are common elements that influence the deterioration of the creditworthiness of the borrower and their ability to properly service the debt to banks in Latin America countries. For this reason, the paper analyzes the impact of the following macro and micro variables, as explanatory variables, on the occurrence and movement of NPLs in equation (xx): The gross domestic product (GDP), ${ }^{1}$ the unemployment rate (UNR), the inflation rate (INF), the household finale consumption expenditure (HFC), the bank's capital to assets (CAR) ratio and the lending interest rate (LIR). The data was collected from the official World Bank website, for the period from 2000 to 2015, for all Latin American countries, except Colombia, for which data are not available. Considering the structural breaks for some of the data, unbalanced panel data set is used.

The research was started by analyzing the basic statistical characteristics of the dependent and explanatory variables. Summary descriptive statistics for all variables shown in Table 1.

The average value of the NPLs is around 4,8\% approximately, which is well below the average rate of NPLs of European emerging countries (see $[10,21]$ ). The maximum value of GPD is up to $10 \%$, which is an indicator of a high rate of economic growth. However, on the other hand, this indicator also records negative values, which means that some Latin American countries were a serious recession. The average level of unemployment is around 7,4\%, which is at the level of some developed countries, however its highest value reaches the amount of about $19 \%$. This indicates that some countries face a significant unemployment problem. The INF takes value from $-1,07 \%$ to $121,7 \%$. High inflation is one of the main problems of Latin America. This especially applies to Venezuela today. The negative rate of INF indicates the occurrence of deflation. The HFC records ranging from - 16,87 to $16,89 \%$. Despite different prudential regulations, average value of the CAR is encouraging. It provides certain security and allows banks to face a certain degree with macroeconomic shocks. The LIR records a relatively high disparity between minimum and maximum, which may indicate that banks differentiated lending rates correctly depending on the client's creditworthiness.

The second step in the analysis was to examine the presence of a unit root in the panel data. For this purpose Im-PesaranShin test was used. Non-stationarity was identified by the UNR and the LIR. In these cases the first difference technique was employed. The results was reported in Table 2.

The correlation matrix is presented in Table 3. As it can be seen from Table 3, there is no strong correlation between the selected variables. For this reason, no variable is excluded from further analysis.

Of the available two-step and one-step GMM, one-step GMM estimator is chosen due to the fact that in smaller sample sizes it tends to be less biased. One-step difference and one-step system GMM estimation results of dynamic model (3.7) are presented in Table 4.

The Sargan over-identification test for both GMM estimations show that all instruments involved are valid. The AR(1) and $\operatorname{AR}(2)$ tests yield the expected diagnosis. So, the AR(1) test rejects the null hypothesis of no first-order serial correlation, but does not reject the null hypothesis that there is no second-order serial correlation. As can be seen from Table 4, the results show that there is strong impact of the GPD on NPLs. This is in line with the prevailing literature of today. But unlike most of the findings that presented the negative correlation between NPLa and GDP, a positive relationship was found here.

\footnotetext{
1 For the purpose of this research and easier interpretation, variable GDP has been transformed into logarithmic function and represents the GDP growth over years.
} 
Table 2

The results of Im-Pesaran-Shin test. Source: Author's calculations.

\begin{tabular}{llll}
\hline Variables & & Critical value & $p$-value \\
\hline \multirow{2}{*}{ NPL } & Level & $-11,679$ & 0,000 \\
& 1st difference & - & - \\
\hline \multirow{2}{*}{ IGDP } & Level & $-2,069$ & 0,020 \\
& 2nd difference & $-2,320$ & 0,010 \\
\hline \multirow{2}{*}{ UNR } & Level & 0,534 & 0,703 \\
& 1st difference & $-1,980$ & 0,023 \\
\hline \multirow{2}{*}{ INF } & Level & $-2,023$ & 0,022 \\
& 1st difference & - & - \\
\hline \multirow{2}{*}{ HFC } & Level & $-1,770$ & 0,038 \\
& 1st difference & - & - \\
\hline \multirow{2}{*}{ CAR } & Level & $-1,751$ & 0,040 \\
& 1st difference & - & - \\
\hline \multirow{2}{*}{ LIR } & Level & $-0,527$ & 0,299 \\
& 1st difference & $-2,819$ & 0,002 \\
\hline
\end{tabular}

Table 3

Correlation matrix.

Source: Author's calculations.

\begin{tabular}{llllllll}
\hline NLP & GPD & UNR & INF & HFC & CAP & LIR & \\
\hline 1,000 & $-0,098$ & 0,279 & $-0,034$ & $-0,486$ & $-0,135$ & 0,401 & NLP \\
& 1,000 & $-0,046$ & $-0,202$ & 0,635 & $-0,164$ & 0,076 & GPD \\
& 1,000 & 0,337 & 0,002 & $-0,202$ & $-0,121$ & UNR \\
& & 1,000 & $-0,132$ & 0,087 & $-0,023$ & INF \\
& & & 1,000 & 0,125 & $-0,023$ & HIP \\
& & & & 1,000 & 0,088 & CAP \\
& & & & & & 1,000 & LIR \\
\hline
\end{tabular}

Table 4

GMM estimation results for dynamic panel data model (2.5).

Source: Author's calculations.

\begin{tabular}{|c|c|c|c|c|c|c|}
\hline \multirow[b]{2}{*}{ Variables } & \multicolumn{3}{|c|}{ One-step difference GMM } & \multicolumn{3}{|c|}{ One-step system GMM } \\
\hline & Coefficient & Std. Error & $p$-value & Coefficient & Std. Error & $p$-value \\
\hline const & 2,101 & 1,216 & 0,084 & 5,542 & 1,740 & 0,002 \\
\hline $\operatorname{NLP}(-1)$ & 0,564 & 0,068 & $<0,0001$ & 0,366 & 0,159 & 0,021 \\
\hline GPD & 1,030 & 0,366 & 0,005 & 1,238 & 0,494 & 0,012 \\
\hline UNR & $-0,069$ & 0,306 & 0,821 & $-0,218$ & 0,344 & 0,525 \\
\hline INF & $-0,086$ & 0,052 & 0,096 & $-0,034$ & 0,027 & 0,213 \\
\hline HFC & $-0,501$ & 0,087 & $<0,0001$ & $-0,532$ & 0,235 & 0,023 \\
\hline CAP & $-0,053$ & 0,093 & 0,572 & 0,043 & 0,105 & 0,681 \\
\hline LIR & $-0,011$ & 0,015 & 0,478 & $-0,010$ & 0,018 & 0,556 \\
\hline Test for $\operatorname{AR}(1)$ & \multicolumn{3}{|c|}{$z=-4,39982[0,0000]$} & \multicolumn{3}{|c|}{$z=-2,03525[0,0418]$} \\
\hline Test for $\operatorname{AR}(2)$ & \multicolumn{3}{|c|}{$z=0,428724[0,6681]$} & \multicolumn{3}{|c|}{$z=1,05636[0,2908]$} \\
\hline Sargan test & \multicolumn{3}{|c|}{ Chi-square $(75)=78,22[0,3757]$} & \multicolumn{3}{|c|}{ Chi-square $(96)=113,948[0,1021]$} \\
\hline
\end{tabular}

Note: Dummies for time effects are used. H-matrix as per Ox/DPD. AR(1) and AR(2) are the Arellano-Bond tests for first and second order autocorrelation of the errors. $p$-values for $\operatorname{AR}(1), \operatorname{AR}(2)$ and Sargan test are shown in parenthesis.

One of explanations for this is that, in the boom period, banks reduce their credited conditions, which, leading to the bank assets quality, deteriorates. A similar finding was presented by Beck et al. [21]. The results show that UNR has no statistically significant impact on NPLs. This can be justified by the fact that banks do not approve loans to unemployed clients or that banks have good loan assurance mechanisms in the event of the borrower losing his or her job. The results also show that INF has no statistically significant impact on NPLs. This is in line with findings reported by Jovovic [18], Skarica [20]. This is a very important finding, especially when it comes to the fact that some Latin American countries have a huge problem with high inflation. The HFC has strong negative impact on growth rate of NPLs. This is expected, taking into account that the costs arising from payment of loans and other fees are included in this indicator. The explanation for this is that the increase in final support leads to economic growth, and that such conditions are favorable for proper loan servicing, and therefore a reduction in the rate of NPLs. A confirmation of this can also be found in the fact that there is a fairly high coefficient of correlation between GDP and HFC. No significant relationship was found between CAR and LIR, as micro variable and NPLs. This finding does not speak of the attitude of banks toward risk-taking activities in cases of favorable capital adequacy. 
However, their credit activities are usually oriented toward less solvency debtors. According to Boudriga et al. [8], when there is no ceiling on lending rates, it is easier for banks to charge a higher risk premium and therefore give loans to more, but we have not found a link between this variable and NPLs. There is a positive and significant correlation between the lagged NPL and current NPLs rate. Since NPLs exhibit a high degree of persistence, this finding is expected. This indicates that a shock to NPLs is likely to have a prolonged effect on the banking system.

\section{Conclusion}

The paper demonstrates the advantages of using GMM in the study of the problem of occurrence, movement and determinants of NPLs, compared to other estimators for estimation panel data models. The demonstration was carried out on the example of emerging countries of Latin America. The aim of the paper is to identify the key macro and micro variables that affect the NPL in these countries.

The findings of the study point out that the GDP has a significant effect on NPLs in emerging countries of Latin America. In other words, a growth in economic activity in these countries is the most important risk for bank asset quality. However, this result is in contradiction with the results presented by Radivojevic and Jovovic [10], who investigated determinates of the NPLs in emerging markets. Findings reveal the existence of a negative relationship between the HFC and NPLs. This finding is expected taking into account that the costs arising from payment of loans and other fees are included in this indicator.

The results show that UNR has no statistically significant impact on NPLs. Also, they show that INF has no statistically significant effect on NPLs. This is in line with findings reported by Jovovic [18], Skarica [20]. This is a very important finding, especially when it comes to the fact that some Latin American countries have a huge problem with high inflation. The study also includes microeconomic factors such as CAP and LLR. However, both estimable methods, GMM difference and GMM system, did not reveal a statistically significant relationship between these variables and NPLs. In accordance with Arrello and Bond's allegations, one step of procedure was used in this paper.

In future studies there is need to apply more advanced methods like computational intelligence methods and artificial neural networks [44-48].

\section{References}

[1] T. Fukuda, J. Dahalan, Finance - growth-crisis nexus in asian emerging economies: evidence from vecm and adrdl assessment, Int. J. Econ. Sci. Appl. Res. 5 (2) (2012) 69-100.

[2] M. Manove, J. Padilla, A, M. Pagano, Collateral versus projectscreening: a model of lazy banks, Rand J. Econ. 32 (4) (2001) $726-744$.

[3] W. Bolt, A.F. Tieman, Banking competition, risk and regulation. IMF Working Paper WP/04/11, 2004.

[4] S. Jeong, H. Jung, Bank wholesale funding and credit procyclicality: evidence from korea, Panoeconomicus 60 (5) (2013) 615-631.

[5] V. Makri, A. Tsagkanos, A. Bellas, Determinants of non-performing loans: the case of eurozone, Panoeconomicus 2 (2014) 193-206.

[6] J.C. Godlewski, Bank capital and credit risk taking in emerging market economies, J. Bank. Regul. 6 (2) (2005) 128-145.

[7] M.T. Garsiya, R.M.D. Fernandez, Risk-taking behaviour and ownership in the banking industry: the spanish evidence, J. Econ. Bus. 60 (4) (2007) $332-354$.

[8] A. Boudriga, N. Taktak, S. Jellouli, Bank specific, business and institutional environment determinants of nonperforming loans: evidence from MENA countries. Paper presented at Economic Research Forum 16th Annual Conference Cairo, 2009.

[9] P.D. Louzis, A.T. Vouldis, V.L. Metaxas, Macroeconomic and bank-specific determinants of non-performing loans in greece: a comparative study of mortgage, business and consumer loan portfolios, J. Bank. Financ. 36 (1) (2012) 1012-1027.

[10] N. Radivojevic, J. Jovovic, Examining of determinants of non-performing loans, Prague Econ. Pap. 26 (3) (2017) 300-316.

[11] V. Salas, J. Saurina, Credit risk in two institutional regimes: spanish commercial and savings banks, J. Financ. Serv. Res. 22 (2002) $203-224$.

[12] R. Espinoza, A. Prasad, Nonperforming loans in the GCC banking szstem and their macroeconomic effects, IMF Working Paper $224,2010$.

[13] I. Babouček, M. Jančar, Effects of macroeconomic shocks to the quality of the aggregate loan portfolio, Czech National Bank, 2005.

[14] L. Rinaldi, A. Sanchis-Arellano, Household debt sustainability: what explains household non-performing loans? An Empirical Analysis. ECB Working Paper, 2006.

[15] M. Nkusu, Nonperforming Loans and Macrofinancial ulnerabilities in Advanced Economies. IMF Working Paper 161, 2011.

[16] R. Mileris, Macroeconomic determinants of loan portfolio credit risk in banks, Inz. Ekon. 23 (5) (2012) 496-504.

[17] S. Figlewski, H. Frydman, W. Liang, Modelling the effect of macroeconomic factors on corporate default and credit rating transitions, Int. Rev. Econ. Finance 21 (2012) 87-105.

[18] J. Jovovic, Determinants of non-performing loans: econometric evidence based on 25 countries (Master thesis), City University London, 2014.

[19] C. Shu, The Impact of macroeconomic environment on the asset quality of Hong Kong's banking sector. Hong Kong Monetary Authority Research Memorandums, 2002.

[20] B. Skarica, Determinants of non-performing loans in Central and Eastern European Countries, Working Paper, 2013.

[21] R. Beck, P. Jakubik, A. Piloiu, Key determinants of non-performing loans: new evidence from a global sample, Open Econom. Rev. 26 (3) (2015) 525-550.

[22] R. Rajan, S.C. Dahl, Non-performing loans and terms of credit of public sector banks in india: an empirical assessment, Occasional Papers, Reserve Bank of India 24 (3) (2003).

[23] G. Hoggarth, A. Logan, L. Zicchino, Macro stress tests of uk banks, BIS Papers 22 (2005) 392-408.

[24] G. Saurina, G. Jiménez, Credit cycles, credit risk, and prudential regulation, Documentos de trabajo del Banco de Espana 31 (2006) 9-34.

[25] I. Saba, Determinants of non performing loans: case of us banking sector, Economic 44 (3) (2012) 81-121.

[26] R. De Bock, A. Demyanets, Bank asset quality in emerging markets: determinants and spillovers, International Monetary Fund Working Paper $\mathrm{WP} / 12 / 71,2012$.

[27] C. Pouvelle, Bank credit, asset prices and financial stability: Evidence from French banks. IMF Working Paper WP/12/103, 2012.

[28] N. Stakic, Determinante kretanja nivoa porblematičnih kredita u bankarskom sektoru u Srbiji, Bankarstvo 4 (2014) 122-146.

[29] B. Mandelbrot, The variation of certain speculative prices, J. Bus. 36 (4) (1963) 394-419.

[30] E. Fama, The behaviour of stock market prices, J. Bus. 64 (1965) 34-105.

[31] J.M. Wooldridge, Introductory econometrics: a modern approach, fourth ed., South-Western Cengage Learning, Mason, Ohio, 2014.

[32] N. Klein, Non-Performing loans in CESEE: determinants and impact on macroeconomic performance. IMF Working Paper, 13/72, 2013. 
[33] M.H. Pesaran, Y. Shin, R.P. Smith, Pooled mean group estimation of dynamic heterogeneous panels, J. Amer. Statist. Assoc. 94 (446) (1999) 621-634.

[34] P. Chausse, Computing generalized method of moments and generalized empirical likelihood with R. Workong paper, 2010.

[35] A. Cottrell, R. Lucchetti, Gretl User's Guide: Gnu regression, econometrics and time-series library, GNU Free Documentation License, 2016.

[36] J. Hwang, Y. Sun, Should we go one step further? An accurate comparison of one-step and two-step procedures in a generalized method of moments framework, 2014 (Manuscript).

[37] C. Heij, P. de Boer, P.H. Franses, T. Kloek, H. van Dijk, Econometric Methods with Applications in Business and Economics, Oxford University Press Inc, New York, 2004.

[38] D. Roodman, How to do xtabond2: an introduction to difference and system gmm in stata, Stata J. 9 (1) (2009) 86-136.

[39] M. Carrasco, A regularization approach to the many instruments problem, J. Econom. (2012) http://dx.doi.org/10.1016/j.jeconom.2012.05.012.

[40] E. Mileva, Using Arellano - Bond Dynamic Panel GMM Estimators in Stata. Tutorial with Examples using Stata 9.0., 2007.

[41] M. Arellano, S. Bond, Some tests of specification for panel data: monte carlo evidence and an application to employment equations, Rev. Econom. Stud. 58 (1991) 277-297.

[42] R. Blundell, S. Bond, Initial conditions and moment restrictions in dynamic panel data models, J. Econometrics 87 (1998) 115-143.

[43] M. Arellano, O. Bover, Another look at the instrumental-variable estimation of error-components, J. Econometrics 68 (1995) $29-52$.

[44] A. Toghroli, E. Darvishmoghaddam, Y. Zandi, M. Parvan, M. Safa, M.A.M. Abdullahi, M..... Khorami, Evaluation of the parameters affecting the schmidt rebound hammer reading using anfis method, Comput. Concr. 21 (5)(2018) 525-530.

[45] A. Toghroli, Applications of the anfis and lr models in the prediction of shear connection in composite beams (Doctoral Dissertation), Jabatan Kejuruteraan Awam, Fakulti Kejuruteraan, Universiti Malaya, 2015.

[46] I. Mansouri, M. Shariati, M. Safa, Z. Ibrahim, M.M. Tahir, D. Petković, Analysis of influential factors for predicting the shear strength of a v-shaped angle shear connector in composite beams using an adaptive neuro-fuzzy technique, J. Intell. Manuf. (2017) 1-11.

[47] M. Mohammadhassani, A. Saleh, M. Suhatril, M. Safa, Fuzzy modelling approach for shear strength prediction of rc deep beams, Smart Struct. Syst. 16 (3) (2015) 497-519.

[48] Y. Sedghi, Y. Zandi, A. Toghroli, M. Safa, E.T. Mohamad, M. Khorami, K. Wakil, Application of anfis technique on performance of $\mathrm{c}$ and 1 shaped angle shear connectors, SMART Struct. Syst. 22 (2018) 335-340. 